\title{
O PROJOVEM URBANO COMO POLÍTICA DE INVISIBILIDADE DA CLASSE TRABALHADORA $^{12}$
}

\author{
Rafael de Lima Bilio ${ }^{3}$ \\ Sonia Maria Rummert ${ }^{4}$
}

\begin{abstract}
Resumo
Este artigo trata, à luz do materialismo histórico, do programa denominado ProJovem Urbano (PJU), que visa atender jovens com idade entre 18 e 29 anos, alfabetizados, mas que não concluíram o 9a ano do Ensino Fundamental. Nesse contexto, evidenciamos que o PJU está inscrito em um processo de intensificação das políticas focais de gestão da pobreza e de invisibilidade da classe trabalhadora, a partir de uma miríade de programas compensatórios de atenuação do desemprego e amortização de conflitos sociais na sociedade brasileira. Para as finalidades desse artigo, utilizaremos o relatório de gestores que contém a análise de cento e oitenta e um questionários aplicados aos gestores do programa que estavam exercendo ou haviam exercido o referido cargo.
\end{abstract}

Palavras-chave: Qualificação Profissional; ProJovem Urbano; Política Assistencial

\section{Resumen}

Este artículo trata del programa denominado ProJovem Urbano (PJU), que busca atender a jóvenes con edad entre 18 y 29 años, alfabetizados, pero que no concluyeron el $9^{\circ}$ año de la Enseñanza Fundamental, a la luz del materialismo histórico. En este contexto, evidenciamos que el PJU está inscrito en un proceso de intensificación de las políticas focales de gestión de la pobreza y de invisibilidad de la clase trabajadora, a partir de una miríada de programas compensatorios de atenuación del desempleo y amortización de conflictos sociales en la sociedad brasileña. Para los fines de este artículo, utilizaremos el informe de gestores que contiene el análisis de ciento ochenta y un cuestionarios aplicados a los gestores del programa que estaban ejerciendo o habían ejercido dicho cargo.

Palabras clave: Calificación Profesional; ProJovem Urbano; Política Asistencial

\footnotetext{
${ }^{1}$ DOI: https://doi.org/10.22409/tn.16i30.p10089

${ }^{2}$ Este artigo está baseado, sobretudo, em Bilio, R. de L. (2017) na tese intitulada "O PROGRAMA NACIONAL DE INCLUSÃO DE JOVENS-URBANO (PROJOVEM URBANO): A CONSTRUÇÃO DO PRECARIADO E A HEGEMONIA DA PEQUENA POLÍTICA".

${ }^{3}$ Doutor em Educação pela Universidade Federal Fluminense. Graduado em Pedagogia pela UNIRIO. Atuou como supervisor do ProJovem e ProJovem Urbano no Sistema de Monitoramento e Avaliação do Programa.

${ }^{4}$ Professora associada da Universidade Federal Fluminense atuando no Programa de Pós-

Graduação em Educação.
} 


\section{Introdução}

Este artigo aborda questão relevante no cenário social e político que a sociedade brasileira vem vivenciando nas últimas três décadas: a educação da classe trabalhadora. Trataremos, aqui, particularmente, de um programa que, apresentado à sociedade brasileira como emergencial e transitório, constitui expressão da lógica que, ao longo da história do país, prevalece nas propostas e ações empreendidas pela classe dominante, visando, nesse caso particular, à (con)formação da parcela mais destituída de direitos da juventude brasileira.

O Programa Nacional de Inclusão de Jovens (ProJovem), objeto da presente análise, em particular o ProJovem Urbano (PJU) será aqui abordado enquanto elemento de mediação histórica dos fenômenos da relação TrabalhoEducação. Como parte de um todo complexo, marcado por continuidades e rupturas, o PJU encontra-se inscrito em um período de intensas ações governamentais de criação de programas de formação, no âmbito da Educação de Jovens e Adultos. Trazendo as marcas do aligeiramento e do reducionismo da educação ao plano da assistência social, constitui expressão recente do caráter de dualidade do sistema educacional brasileiro sob suas atuais configurações.

Acreditamos que a consideração da particularidade histórica do PJU pode indicar caminhos para a compreensão da miríade contemporânea de programas educacionais fundamentados na política de "invisibilidade da classe trabalhadora" (RUMMERT, 2009), tal como explicitado, ainda no ano de 2007, pela Agência Estado, ao afirmar que o ProJovem constituía uma oportunidade para que "as pessoas que necessitam de amparo a assistência social possam sobreviver às próprias custas e, assim, ser responsáveis e tomar conta de si mesmas" (2007, Diário de Tarde, apud. RUMMERT, idem, p.215-216).

O "tomar conta de si mesmas" respalda-se numa dupla lógica, que não se fundamenta no princípio do direito: por um lado, objetiva desonerar o Estado no âmbito dos gastos públicos, por outro visa, sobremaneira, o controle social. Essa lógica, que acompanha os diferentes estágios de expansão e consolidação do modo de produção capitalista, fica muito clara ao analisarmos as proposições dos organismos multilaterais de financiamento, como por exemplo, o Banco Mundial. Conforme assinalava Leher, ainda no final da década de 1990, a forte preocupação com a pobreza e com suas consequências políticas é visível nos 
documentos e nas declarações dos dirigentes (1999) como, por exemplo, no caso do então presidente do referido banco: "as pessoas pobres do mundo devem ser ajudadas, senão elas ficam zangadas" (CAUFIELD, 1996, p. 315, apud. LEHER, 1999, p.24).

Considerando-se serem os chamados pobres ${ }^{4}$ aqueles que "no momento presente se acham excluídos do nosso sistema econômico, por acaso, infortúnio ou falta de competência", como advogava Galbraith (1961. Apud GEREMEK, 1995, p. 09), justificam-se as ações de caráter educativo destinadas, supostamente, a reverter o quadro individual/familiar, favorecendo acesso precário a fragmentos de conhecimento que irão possibilitar a incorporação periférica e precária nas franjas do processo produtivo.

$\mathrm{Na}$ verdade, as políticas de governo, no âmbito da educação, são aqui compreendidas basicamente como uma das expressões da forma como o Estado capitalista administra a correlação das forças sociais, preservando os interesses dominantes, mas contemplando, também, de forma subordinada, as demandas das classes subalternizadas, objetivando a mediação de interesses em conflito e, em decorrência, a manutenção da hegemonia e das condições de controle social.

Assim, ao analisarmos a materialidade das políticas para a educação básica e profissional da classe trabalhadora, constituída pelos instrumentos legais bem como pelas ações implementadas ou induzidas pelo Governo Federal, estaremos apreendendo o conteúdo das características que assume, no atual momento histórico, o conflito estrutural entre Capital e Trabalho. A apreensão das formas assumidas por esse conflito constitui chave para compreender, por exemplo, dados divulgados pelo IBGE, na Síntese de Indicadores Sociais, publicada em dezembro de 2017.

A análise dos dados evidencia o fato de que a mobilidade social, no Brasil, permanece marcada pela injustiça e pela concentração de renda, típicas do capitalismo dependente (FERNANDES, 1973) e das formas como o

\footnotetext{
${ }^{4}$ Em detido estudo sobre a miséria na Europa, desde a Idade Média, Geremek, ao abordar as relações entre o mundo contemporâneo e a miséria, afirma: "A criação de possibilidades de trabalho constitui uma forma de assistência social e, ao mesmo tempo, de luta contra a decadência moral social. Nas visões utópicas de reformação social que proliferam na literatura da Europa moderna, o trabalho aparece como uma panaceia quer contra a miséria, quer contra a delinquência. Aos olhos do homem moderno, a degradação moral causada pela pobreza anda a par com a depravação nascida de uma vida ociosa às custas da sociedade" (1995, p.276).
} 
desenvolvimento desigual e combinado ${ }^{5}$ se materializam no país. Desde os primeiros estudos acerca da questão, dentre os quais se destaca o de Pastore (1979), se evidencia o fato de que nas frações de classe situadas na base da pirâmide social, massivamente constituída pelos trabalhadores sem qualificação, verifica-se, sobretudo, o que é tecnicamente denominado como "mobilidade de curta distância". Já ao final da década de 2010, a mais recente pesquisa do IBGE, informa que entre os estratos mais baixos de classificação adotada pelo órgão, a mobilidade permanece com as mesmas características verificando-se que a transição, no mundo do trabalho, permanece circunscrita às possibilidades do trabalho simples, tal como formulado por Marx no volume 1 de O Capital, de 1987 (MARX, 1988). Assim, por exemplo, os filhos de trabalhadores rurais deslocamse, predominantemente para outras ocupações que envolvem também o trabalho simples, como serventes ou empregados domésticos caracterizados por requerimentos de baixa qualificação.

Neste cenário de preservação da desigualdade social, é evidente a necessidade de ações que concorram, minimamente, para que os pobres não fiquem zangados, como ensinado pelo Banco Mundial. Abre-se, assim, um largo espaço para as ações de assistência social, muitas vezes revestidas de roupagens de caráter educacional, como no caso do ProJovem, como veremos adiante. A relevância dada à assistência social no Brasil, em detrimento do respeito aos direitos objetivos e subjetivos da classe trabalhadora, pode ser percebida, na atualidade, por exemplo, pela quase equivalência que os gastos da União em relação às despesas totais líquidas apresentam, se comparamos o destinado à educação e à assistência social.

Segundo estudo de Gustavo Machado, baseado nas séries históricas do Tesouro Nacional, no período de 2010 a 2016 (ILEASE, 2017, p.23), foi gasto um total aproximado de oitenta e quatro bilhões em Educação e, em Assistência Social, setenta e sete bilhões, aproximadamente. Cremos que a diferença de sete bilhões entre as duas rubricas evidencia, de forma eloquente, o grau de prioridade efetivamente atribuído à educação, em específico a da classe trabalhadora, sobretudo se comparada à relevância das funções de controle inerentes à

\footnotetext{
${ }^{5}$ Desenvolvida por Trotsky e incorporada por Florestan Fernandes à análise da realidade brasileira.
} 
Assistência Social que tem por alvo, especificamente, as frações da classe trabalhadora mais destituídas de direitos.

É, precisamente aos jovens dessas frações de classe que se destina o ProJovem, desde 2005, como será explicitado adiante. Para empreender a análise, apresentaremos, inicialmente, uma breve reconstrução histórica de sua implementação, com ênfase no ProJovem Urbano.

O histórico analítico do ProJovem foi objeto de vários estudos já publicados. Entre eles, podemos destacar: Cabral, M; Cêa, G.; Silva, S. (2017), e Viriato; Cêa; Cavalcante (2007). Também deve ser destacado, especialmente, o trabalho de BILIO (2017) e a produção de Rummert, S.; BILIO, R. e Gaspar, L. (2017); Silva, J.P. (2011) que analisaram a implementação nacional ${ }^{6}$ e regional do programa com fontes primárias, dados e fatos pouco acessíveis. Em decorrência, neste artigo, serão feitas referências apenas a aspectos pertinentes à argumentação desenvolvida.

\section{Construção governamental do ProJovem}

Em 2004, o governo federal constituiu um Grupo Interministerial da Juventude, coordenado pela Secretaria Geral da Presidência da República (SGPR) e composto por dezenove de seus ministérios, com o objetivo de formular uma Política Nacional de Juventude para população com faixa etária de 15 a 29 anos com baixa escolaridade, baseando-se na Pesquisa Nacional por Amostragem de Domicílios (PNAD/2003) e nas propostas dos movimentos de juventude (BRASIL,2010a).

Com a finalidade de "gerar a oportunidade para esses jovens recuperarem e continuarem seus estudos, ampliando, assim, suas perspectivas de inclusão no mercado de trabalho e na sociedade em geral" (BRASIL, 2010a, p. 9), o ProJovem foi instituído por meio da Medida Provisória no 238/2005 (BRASIL, 2005c), transformada na Lei o 11.129/2005 (BRASIL, 2005b) e regulamentada pelo Decreto oㅜ 5.557/2005 (BRASIL, 2005a). Concomitante a isso, ocorreu o

\footnotetext{
${ }^{6}$ A tese de Bilio, R.L. (2017) reconstitui a criação do PJU a partir de 2007, como ambiente de experimentação sociopolítica e analisa os aspectos teórico-metodológicos que respaldam as ações formativas da qualificação profissional do PJU, considerando como campo empírico o período referente à $6^{\mathrm{a}}$ entrada do programa (2010) e os dados do Sistema de Monitoramento e Avaliação (SMA).
} 
lançamento da Secretaria Nacional de Juventude (SNJ) e do Conselho Nacional de Juventude (CNJ) (BRASIL, 2010a).

O ProJovem obteve da Câmara de Educação Básica do Conselho Nacional de Educação o Parecer CNE/CEB ํㅜ 2/2005 (BRASIL, 2005d), com a designação de curso experimental, o que possibilitou a certificação dos alunos. Entretanto, apenas em 2006, com o Parecer CNE/CEB no 37/2006 (BRASIL, 2006), foram aprovadas as diretrizes e os procedimentos técnico-pedagógicos para a implementação do Programa (BRASIL, 2008a).

O ProJovem foi apresentado como programa emergencial e gerido pela Coordenação Nacional do PJU, vinculado à SNJ articulando o Ensino Fundamental, a Qualificação Profissional (QP) e a Ação Comunitária em um Projeto Pedagógico Integrado (PPI). O ProJovem Original ${ }^{7}$, destinava-se aos jovens entre 18 e 24 anos, estruturando-se inicialmente da seguinte maneira: Formação Básica, desenvolvida em oitocentas horas, trezentos e cinquenta de QP, cinquenta horas presenciais de Ação Comunitária, perfazendo um total de mil e duzentas horas presenciais e quatrocentas horas não presenciais, distribuídas em doze meses. Os alunos matriculados no programa receberiam um auxílio financeiro mensal de $R \$ 100,00$, condicionado à frequência mínima de $75 \%$ e à entrega dos trabalhos obrigatórios do mês (ibid.).

Durante o período de funcionamento, o ProJovem Original atendeu "241.235 alunos distribuídos em 57 capitais e regiões metropolitanas pelo país [...]. Desse total de matrículas, 146.451 , de fato, chegaram a cursar o programa, e 106.504 o concluíram" (BRASIL, 2010a, p. 10).

Além dos critérios de acesso baseados na idade e na exigência de escolaridade, o parâmetro mais contraditório da política nacional de inclusão de jovens foi a exigência de o aluno não possuir vínculo formal de trabalho. $O$ início do ProJovem como Programa Nacional de Inclusão de Jovens foi marcado pela relação do não acesso daqueles que possuíam vínculos formais de trabalho. Esse ponto foi objeto constante de discussões, que culminou no reconhecimento do próprio programa, em seu relatório final de gestão, quanto ao "[...] perfil dos jovens atendidos, [que] revela ser necessário evitar obstáculos à sua inserção no

\footnotetext{
7 A denominação "ProJovem Original" refere-se à nomenclatura utilizada pelos órgãos governamentais para diferenciar o precursor do PJU no campo das políticas públicas de juventude.
} 
Programa, tais como as exigências de conclusão da $4^{\underline{a}}$ série do Ensino Fundamental e de não existência de vínculo formal de trabalho" (BRASIL, 2008a, p. 16). Ficou notório que: "Em alguns casos, a própria obtenção de emprego com carteira assinada foi indicada como causa de evasão do Programa" (ibid., p. 17).

Os demais problemas observados nos relatórios de avaliação do programa consistiam na demora ou na ausência da construção dos laboratórios de informática. Em alguns municípios, a falta de computadores, a carência de merenda ou sua péssima qualidade, atraso nos salários dos professores, a falta de aulas práticas de QP foram fatores que desestimularam os alunos.

A partir da experiência do ProJovem Original e com o argumento de articular as ações voltadas para os jovens, em 2007, o governo federal reuniu um grupo de trabalho denominado "GT Juventude", composto de representantes da Secretaria-Geral da Presidência da República, da Casa Civil e dos Ministérios da Educação, do Desenvolvimento Social, do Trabalho e Emprego, da Cultura, do Esporte [...]" (BRASIL, 2010c, p. 8). Concomitantemente ao trabalho do GT Juventude, nesse mesmo ano, foram realizados estudos para "[...] definir o público potencial do PJU, a Coordenação Nacional do PJU, juntamente com a equipe técnica do Centro de Políticas Públicas e Avaliação da Educação CAEd/UFJF" (ibid., p. 51). Para definição do público potencial considerou-se o estudo populacional baseado nos dados do Instituto Brasileiro de Geografia e Estatística (IBGE), nas séries históricas do Censo Populacional e das Pesquisa Nacional por Amostra de Domicílios (PNAD-2005 e 2006), além da Estimativa 2006, do Sistema IBGE de Recuperação Automática (SIDRA) e da Contagem Populacional 2006 (ibid.).

Sob a alegação de ampliar a Política Nacional de Juventude, foi lançado o ProJovem Integrado, pela Medida Provisória o 411/2007 (BRASIL, 2007) posteriormente regulamentada pela Lei oㅜ 11.692/2008 (BRASIL, 2008a) -, que foi estruturado em quatro programas: ProJovem Urbano (objeto deste artigo); ProJovem Adolescente ${ }^{8}$, ProJovem Campo ${ }^{9}$ e ProJovem Trabalhador ${ }^{10}$.

\footnotetext{
${ }^{8}$ Objetiva complementar a proteção social básica à família e gerar as condições de acesso do jovem no sistema educacional. Executada pelo Ministério do Desenvolvimento Social e Combate à Fome (MDS).

${ }^{9}$ Objetiva oferecer qualificação profissional e escolarização aos jovens agricultores familiares de 18 a 29 anos que não concluíam o ensino fundamental. Único dos quatro que, naquele período sob a efetiva responsabilidade do Ministério da Educação (MEC).
} 
Desse modo, os quatro novos programas - mantiveram, em grande parte, as orientações sociopolíticas e culturais de caráter emergencial e voltados para grupos específicos - com as mais variadas durações. A experiência transitória e experimental do ProJovem Original ganhou um espaço maior como política de juventude, com a criação do ProJovem Integrado, no qual ampliou-se e prolongou-se a faixa etária das políticas de juventude para os vinte e nove anos. Essa política de juventude foi alicerçada pela reeleição do presidente Luis Inácio Lula da Silva.

No entanto, os quatro programas que compõe o ProJovem Integrado apostaram de distintas formas de ensino - predominantemente na Qualificação Profissional, prevista pelo Decreto № 5.154/2004 (BRASIL, 2004) -, mas foram incapazes de reverter a desvalorização sociocultural desse modelo, que, no plano histórico, sempre foi relegado às frações mais expropriadas da classe trabalhadora.

Destaca-se, porém, que, apesar de ter o ProJovem Original como modelo de implementação e de desenvolvimento, o PJU também ampliou sua carga horária para duas mil horas e sua duração para dezoito meses, mas manteve os três pilares do PPI, a saber:

a) Formação Básica - desenvolvida em mil e noventa e duas horas, com o objetivo de garantir aprendizagens determinadas nas Diretrizes Curriculares Nacionais para o Ensino Fundamental, e baseada na Qualificação Profissional bem como na Participação Cidadã;

b) Qualificação Profissional Inicial - desenvolvida em trezentos e noventa horas, com o objetivo de preparar os jovens para atuar no mundo do trabalho por meio da Formação Técnica Geral (FTG) e dos Arcos Ocupacionais ${ }^{11}$;

c) Participação Cidadã - desenvolvida em setenta e oito horas presenciais e quatrocentos e quarenta horas não presenciais, com o

\footnotetext{
${ }^{10}$ Objetiva a oferta de qualificação profissional para preparar o jovem para inserção no mercado de trabalho. Executada pelo Ministério do Trabalho e Emprego (MTE).

${ }^{11}$ Conjuntos de ocupações com "base técnica comum, que podem abranger as esferas da produção e da circulação (indústria, comércio, prestação de serviços)", aumentando as possibilidades de "inserção ocupacional do/a jovem trabalhador/a (assalariamento, auto emprego e economia solidária)" (BRASIL, 2010a p. 15).
} 
objetivo de garantir aprendizagens sobre direitos sociais e buscar a mobilização do jovem no desenvolvimento de ações comunitárias.

A assinalar, ainda, que com o propósito de aumentar o número de matrículas, passou-se a exigir somente que o aluno soubesse ler e escrever, devendo a matrícula ser realizada de modo descentralizado pelos estados/municípios por meio de sistema informatizado. Os trabalhadores com carteira assinada passaram a ter direito à matrícula, ao contrário do que ocorria no ProJovem Original.

O programa seguiu uma estrutura de implementação segundo a qual os governos estaduais atenderiam os jovens residentes em municípios com população inferior a 200 mil habitantes, e as prefeituras seriam as executoras nos municípios com população superior a esse número (BRASIL, 2010c). Durante a execução do PJU pela coordenação nacional, vinculado à SNJ ocorreram seis entradas $^{12}$ no país. A primeira entrada do programa ocorreu em setembro de 2008; a 2ª em abril de 2009; a 3aㅡ, em junho de 2009; a 4ª , em agosto de 2009 (sendo exclusiva em unidades prisionais); a 5ª , em outubro de 2009; e, por último, a 6aㅗ, em maio de 2010 (BRASIL, 2011a). De 2008 a 2010, o PJU registrou um total de "491.500 jovens matriculados [...], tendo a participação de 118 entes federados que aderiram ao programa, 96 Municípios e 22 Estados" (BRASIL, 2010c, p.52). Além de previstas pelos "estudos de demanda", as seis entradas cumpriram um papel de afirmação político-institucional das políticas de juventude antes de o programa ser transferido para o Ministério da Educação e Cultura (MEC) em 2012.

O aspecto crucial a destacar reside no fato de que as políticas de juventude, no período, vão paulatinamente assumindo um caráter orgânico referente à sua institucionalização como política pública nas esferas governamentais, articulando, de modo fragmentado e deturpado, reivindicações dos movimentos de juventude referentes à necessidade de programas específicos de elevação da escolarização articulados com a educação profissional. Apesar de funcionar como aparente reconhecimento da agenda dos movimentos de

\footnotetext{
${ }^{12} \mathrm{O}$ termo "entrada" designa a criação nacional de novas turmas - autorizada pela Coordenação Nacional do ProJovem Urbano - e o efetivo momento do início das aulas.
} 
juventude, a forma como foi implementado o Programa, realimentou, na verdade, a política estigmatizante para os "desvalidos de sorte" do século XXI.

Nesse sentido, o PJU compõe uma rede paralela de escolas ${ }^{13}$, nas quais os destinatários seriam os "novos-velhos" desfavorecidos de sorte ou de fortuna do século $X X I$, preservando e retomando o critério de miserabilidade característico do Decreto no 7.566/190914 (BRASIL, 1909). Ao reatualizar, no campo da juventude, a noção de desvalidos de sorte ou de fortuna, - crianças e jovens abandonados, órfãos que não que não encontravam meios de garantir sua subsistência - PJU se configurou como nova panaceia quer contra a miséria, quer contra a delinquência, como assinalado por Geremek (op. cit.).

\section{A marca social do ProJovem Urbano}

Os elementos que evidenciam uma forte marca social do PJU na construção de uma invisibilidade da classe trabalhadora consistem na construção de um tipo de escola específica para cada grupo social, perpetuando as desigualdades socioeconômicas e socioculturais com o processo de negaçãoconservação explicitados por Gramsci (2006).

Nesse sentido, constroem-se narrativas para adquirir o consenso da classe trabalhadora, pregando a necessidade "[...] de experiências educacionais diferenciadas, que considerem as características particulares da juventude brasileira, a fim de reedificar o seu vínculo com a escola [e] [...] com intervenções pedagógicas planejadas" (BRASIL, 2011c, p. 11). Essa é a narrativa institucional do PJU, que legitima o aligeiramento e a superficialidade dos conhecimentos construídos historicamente: "Assim sendo, durante 18 meses, os jovens têm acesso a uma formação em que a Educação Básica, a educação para o trabalho e a ação comunitária estão interligadas numa dinâmica intensa e veloz" [grifo nosso] (ibid., p. 15).

\footnotetext{
${ }^{13}$ Para viabilizar o PJU, porém, no mais das vezes, precisou-se recorrer à estrutura das redes públicas de ensino, principalmente aquelas que tinham a EJA em funcionamento. No plano de implementação do programa, havia a obrigatoriedade de o PJU ser aberto em escolas da rede pública de ensino (BRASIL, 2008b, p. 9). Estamos mencionando que a rede paralela apesar de funcionar no espaço escolar institucionalizado, tinha uma série de diferenças sócio-políticas no seu interior (em muitos locais, o espaço reservado ao ProJovem era discriminatório em pequenas ações que atingiam professores e alunos).

${ }^{14} \mathrm{O}$ decreto 7.566 de 23 de setembro, cria as Escolas de Aprendizes Artífices, inicialmente em diferentes Estados sob a jurisdição do Ministério dos Negócios da Agricultura, Indústria e Comércio, destinadas ao ensino profissional, primário e gratuito.
} 
A argumentação do PJU expressa e dissimula, ao mesmo tempo, o elemento ideológico de manutenção das classes hegemônicas pela busca do consenso, combinando uma formação aligeirada e de coerção para fixar novos comportamentos e novas atitudes. Nessas intervenções públicas, exemplificadas pelo PJU, expressa-se o desenvolvimento de programas de educação com viés assistencialista e de fiador do "amortecedor social das classes potencialmente conflitivas" (PETRAS, 1999, p. 44).

O PJU está inscrito em um processo sócio-histórico que permeou a marca social de uma concepção de assistência social na educação remodelada pelo discurso da falta de qualificação e de comportamentos sociais como mal social ${ }^{15}$ dos jovens.

Para as finalidades desse artigo, utilizaremos o relatório de gestores (BRASIL,2011b) abrangendo a análise de questionários aplicados aos gestores do programa (da $3^{\mathrm{a}}$ a $6^{\mathrm{a}}$ entrada) em novembro de 2010 , que haviam exercido ou estavam exercendo ${ }^{16}$ o referido cargo e que eram os responsáveis pela implementação e pelo desenvolvimento do programa na esfera municipal ou estadual. Foram aplicados cento e oitenta e um questionários ao conjunto de coordenadores executivos e pedagógicos (gestores locais) ${ }^{17}$, sendo cento e cinquenta gestores municipais, e trinta e um gestores vinculados à coordenação estadual conforme o plano amostral presente nos cadernos temáticos ${ }^{18}$ do PJU no relatório dos gestores (BRASIL, 2011b, p. 78-82).

Dos 31 Coordenadores Estaduais pesquisados, $48 \%$ são Coordenadores Executivos e 48\% Coordenadores Pedagógicos.

\footnotetext{
${ }^{15}$ Vieira Pinto $(2010$, p. 92) ressalta que esse discurso de mal social para algumas formas do modo de ser do homem demarca um caráter patológico. Ao desconsiderar as condições de existências do indivíduo, "[...] o defeito desta concepção está em quem converte a educação em terapêutica". Há, também, a questão do controle social e a influência da Teoria do Capital Humano.

${ }^{16}$ Também havia uma rotatividade entre os gestores do programa (coordenadores executivos e pedagógicos), o que permitia, muitas vezes, uma mudança na equipe pelas influências políticas ou referentes às lacunas de seu funcionamento. $\mathrm{O}$ reflexo consiste em que "grande parte dos coordenadores entrevistados (46\%) que ingressaram no programa apresentaram uma taxa de permanência de 1 ano e 1 mês a 2 anos" e os gestores que trabalharam no ProJovem Original não chegaram a atingir 10\% dos entrevistados que continuavam trabalhando no PJU (BRASIL,2011b, p. 42.).

17 "Como se tratava de um universo relativamente pequeno, e dado os objetivos do estudo, optouse por trabalhar com todos os coordenadores em vez de se escolher uma amostra aleatória" (BRASIL,2011b, p.13).

${ }^{18} \mathrm{O}$ modelo de questionário aplicado consta no referido relatório (BRASIL, 2011b, p. 85-100).
} 
Já dos 150 Coordenadores Municipais, 47\% desempenharam a função de Coordenadores Executivos e $48 \%$ de Coordenadores Pedagógicos. (BRASIL, 2011b, p. 38).

Dessa forma, a importância de resgatar alguns dados sobre o perfil dos gestores e de suas concepções ${ }^{19}$ acerca do programa permite visualizarmos a concepção de mera política de assistência social conforme o gráfico a seguir:

Gráfico 1: Declaração dos gestores do PJU a respeito da concepção do programa

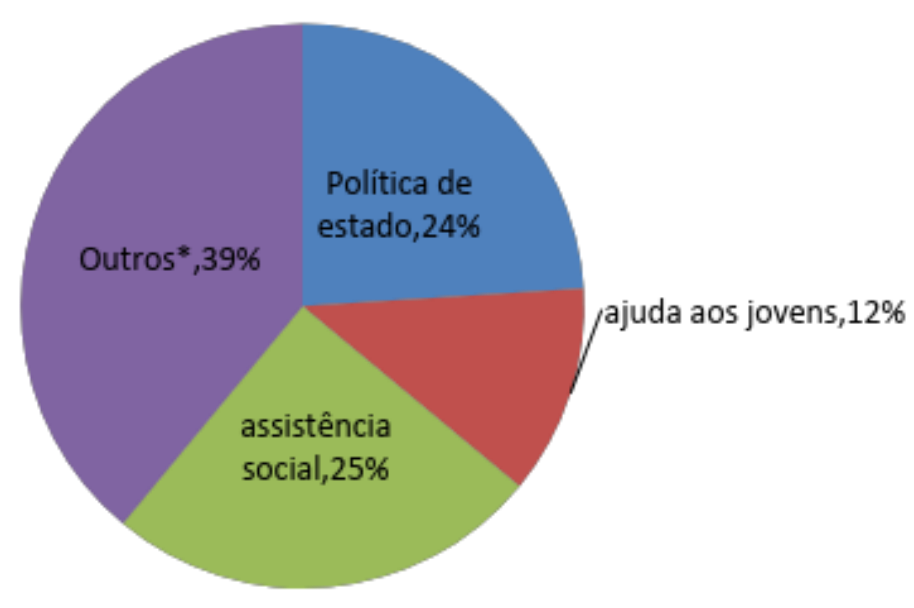

Adaptado de: Brasil, 2011c, p.67

Portanto, para 25\% dos gestores, trata-se de assistência social de forma explícita, aos quais se somam outros $12 \%$ que concebem o PJU como um como uma forma de "ajuda aos jovens". Não conseguimos categorizar o segmento Outros, porque há lacunas nas informações apresentadas no relatório. Por isso, só expusemos os dados que estavam inteligíveis (cf. id., 2011b, p. 67). Entretanto, há uma forte vinculação do PJU com o entendimento de que seja uma política de educação. Percebe-se, assim, uma significativa marca social que aproxima o PJU de um sistema público de socorros e oficinas de caridade remanescentes das poor laws inglesas ${ }^{20}$. O aspecto mais evidente é a perpetuação da concepção da educação:

\footnotetext{
${ }^{19}$ No PJU havia um Formação Inicial e Continuada para formação dos gestores locais (coordenadores e pessoal de apoio) de 56 horas que envolvia as principais concepções do programa, gestão inter-setorial e aspectos administrativos.

20 Esse discurso remonta aos elementos sócio-históricos das referências às poor laws inglesas como oficinas de caridade que abrangeram oportunidades de trabalho locais, mas que visaram a
} 
[...] como dever moral da fração adulta, educada e dirigente da sociedade. Esta ingenuidade é grave, porque converte a educação em ato caritativo e transfere para o plano dos valores éticos (inteiramente alheios a este problema) a essência, 0 significado e a valoração eminentemente sociais da educação. (VIEIRA PINTO, 2010, p. 64).

A lógica presente na percepção dos gestores é expressão da lógica mais ampla que levou à localização institucional do programa nas secretarias municipais ou estaduais de assistência social, o que representou um grave retrocesso no que se refere à transferência de ações de caráter educacional para órgãos de assistência social, como foi, principalmente, o caso observado no gráfico a seguir:

Gráfico 2: Declaração dos gestores do $\mathrm{PJU}^{21}$ sobre quais as secretarias ou órgão públicos que o Projovem já se articulou

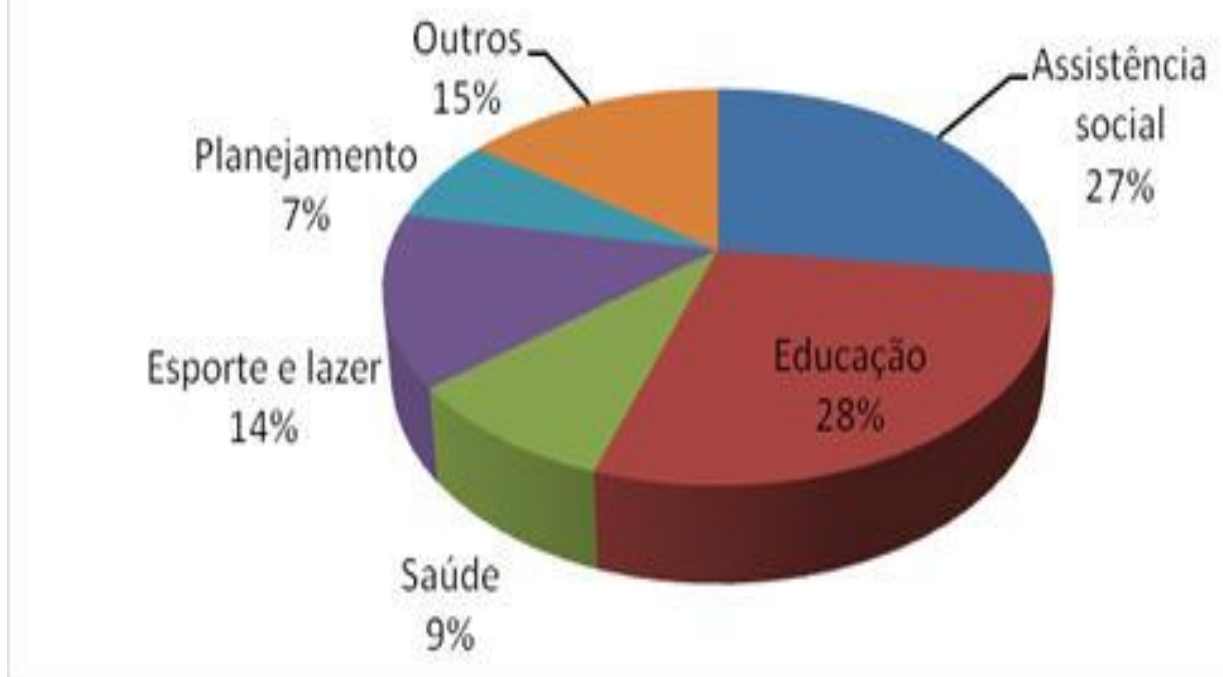

Fonte: Brasil, 2011c, p. 67.

Ao serem indagados sobre a que secretarias, desde a $1^{\text {a }}$ entrada, o PJU22 já se articulou a maioria das respostas dos gestores citava as Secretarias de

um espectro mais amplo de pessoas - em princípio ao conjunto dos jovens da classe trabalhadora mais pauperizada que não conseguiam se inserir no mundo do trabalho na Inglaterra nas primeiras décadas do século XIX (CASTEL, 2008).

${ }^{21}$ Procuramos manter os mesmos títulos dos gráficos apresentados no relatório de gestores (BRASIL,2011b). 
Educação e Assistência Social. Foi constatado, ainda, que apenas $28 \%$ dos gestores responderam ${ }^{23}$ que o programa já se articulou à Secretaria de Educação, enquanto $27 \%$ mencionaram a Secretaria de Assistência Social ou outros setores. Verifica-se, assim, que, majoritariamente, em seus primeiros anos, o programa foi intencionalmente deslocado da alçada da educação. É importante assinalar, ainda, que o próprio Projeto Pedagógico Integrado (PPI) do PJU propiciava tal procedimento, como podemos constatar, por exemplo, na seguinte passagem:

Cada Estado, Município ou DF integrante do ProJovem Urbano contará com: (a) um Comitê Gestor Local, formado por representantes das secretarias estaduais, municipais ou do DF, responsáveis pelas áreas de juventude, educação, desenvolvimento/assistência social e trabalho. Outras secretarias também poderão fazer parte desse Comitê como forma de potencializar as ações do ProJovem Urbano; [grifo nosso] [...]. (BRASIL, 2008a, p. 25).

Como podemos depreender, o PJU poderia estar inserido em qualquer secretaria que tivesse "alguma responsabilidade" com a área de juventude, apesar de ser proclamado como um programa de educação. No ProJovem Original, esse fenômeno era mais agudo quando se considerava o vínculo "orgânico" da coordenação municipal do programa pelas Secretarias de Assistência Social24. Entretanto, no PJU, o vínculo direto com as Secretarias de Assistência Social vai paulatinamente sendo reduzido no período que antecede a transferência do programa para o MEC, principalmente a partir do final de 2010 . Entretanto, deve-se registrar que por quase meia década, não foi considerado o fato de que o PJU é um programa de educação, não sendo, portanto, aceitável alocá-lo em outras esferas, em particular, nas Secretarias de Assistência Social.

A pesquisa em que se baseia este artigo foi realizada na fase final do PJU, quando o programa estava atrelado à Coordenação Nacional no momento

\footnotetext{
${ }^{22}$ Não conseguimos os dados referentes ao ProJovem Original, mas o número de Secretarias de Assistência Social que gerenciavam o programa era significativamente maior no período de 2005 até o início de 2007.

${ }^{23}$ Importante assinalar que quase $10 \%$ dos pesquisados não sabiam informar ou não responderam à questão (BRASIL,2011b, p.66).

${ }^{24}$ Lembramos que no PJU, as Organizações Não Governamentais (ONGs) exerceram um papel significativo no processo de gerenciamento e de implementação - inclusive algumas eram contratadas para as ofertas dos Arcos Ocupacionais da Qualificação Profissional, e para a contratação e o pagamento dos professores do PJU.
} 
precedente a transferência para o MEC. Nesse período, observamos a redução do número de Secretarias de Assistência Social, que veio acompanhada do correspondente deslocamento para as Secretarias de Educação, conforme as novas diretrizes do MEC; ainda assim, o quantitativo das Secretarias de Assistência Social continuou expressivo.

A partir do momento em que o programa foi transferido para o MEC, em 2012, haveria alguns dispositivos de responsabilização das Secretarias de Educação quanto a seu desenvolvimento e a sua implementação. Assim, as respostas referidas no Gráfico 2, sobre a qual secretaria (ou outro órgão público) o PJU já se articulou, indica a gradual migração para as Secretarias Municipais e Estaduais de Educação e predominância dessa vinculação (69\%). Entretanto, a vinculação às Secretarias Municipais e Estaduais de Assistência Social manteve na faixa de $14 \%$ e nas incipientes secretarias de juventude com $7 \%$ (BRASIL,2011b, p.66).

Cabe ressaltar, porém, que a vinculação do programa às Secretarias de Educação não representou a solução dos problemas relativos ao Programa, oriundos de concepções originais equivocadas que, como já assinalado, constituem uma expressão das funções de controle social em detrimento da concepção de educação.

Entretanto, existia outra contradição

[...] quando são analisados os depoimentos dos gestores locais. Quando estes se referem ao conceito do ProJovem demonstram que não está presente a compreensão da vinculação do Programa à política de juventude. Uma possível explicação para tal situação pode ser atribuída ao fato de que os gestores locais conforme os relatos, não tem participação em movimentos ligados à juventude (63,37\%). (BRASIL, 2011b, p.28).

Ora, a inquietação já é grande ao depararmos com a concepção do programa vinculado a esfera da assistência social, mas torna-se totalmente contraditório quando os gestores responsáveis pela implementação do Programa Nacional de Inclusão de Jovens, não o identificam com as políticas de juventude. Será uma simples falta de participação dos gestores nos movimentos de juventude? Será um incompreensão teórico-metodológica dos gestores? Esse ponto é apenas uma das muitas contradições presentes no programa. 
Ademais, o programa fortaleceu o estigma da criminalidade potencial dos jovens das frações mais pauperizadas, consideradas classes perigosas (cf. RUMMERT, 2007), ao remodelar o discurso do mito da marginalidade, quando afirmava-se, por exemplo, que:

O baixo nível de renda acessado pelos jovens no mercado de
trabalho constitui-se em mais um fator de desinteresse - ou até
mesmo para o desalento - de parte desses jovens em ingressar
nesse mercado. Além disso, devido a fatores socioeconômicos e à
idade, aliados à grande oferta da força de trabalho jovem e
problemas na demanda relativa devido à baixa qualificação
[grifo nosso], as dificuldades de ingresso na vida profissional e a
obtenção dos recursos esperados podem conduzir os jovens a
catarem vias não convencionais para atingirem o padrão de
vida almejado, muitas vezes envolvendo a ilegalidade e a
marginalidade [grifo nosso]. (BRASIL, 2010a, p. 29).

O ProJovem Urbano muitas vezes acabou configurando-se como um espaço para o jovem não se desvirtuar, não ceder às tentações do mundo do crime, solidificando a formulação do programa como casas de correção da potencial marginalidade da classe trabalhadora juvenil revelando, explicitamente, o dualismo escolar e a destinação do ensino profissional para os mais pobres. Essas influências trouxeram ao PJU o estigma de uma modalidade de ensino pobre, destinada aos pobres, desfavorecidos e esquecidos pela sociedade - uma espécie de ensino pré-vocacional que os tiraria das ruas e evitaria um possível desvio de caminho (CUNHA, 2005).

\section{Considerações finais}

A identificação dos pressupostos e das características do PJU constituiu importante mediação para o reconhecimento das contradições internas dos aparelhos privados de hegemonia, que se apresentaram como instrumento social de construção moral e psicofísica da classe trabalhadora, servindo para polarizar a noção de competências - sobretudo no plano comportamental - como fundamento de suas ações formativas, mantendo modelos vigentes no padrão taylorista-fordista.

O PJU surgiu na sequência de criação de uma série de programas criticados pela aligeiramento na formação, pela ineficácia na diminuição do 
desemprego, pelo caráter ultrafocalizado do público-alvo e pelas conhecidas condições de acesso ao programa devido à pauperização socioeconômica. A marca social da assistência social em detrimento da política educacional pode ser vislumbrada nos gráficos, a partir das respostas dos gestores que eram os responsáveis pela implementação do PJU nos municípios e estados. Portanto, trata-se de visualizar a materialidade político-pedagógica dos mediadores da dessa política aligeirada e compensatória do PJU.

Um dos objetivos do PJU consistiu na melhoria dos dados relativos ao fluxo de matrículas de alunos da rede escolar, valendo-se de um discurso democratizante, preocupado com a inserção da força de trabalho juvenil, que podia amenizar (e não superar) o pauperismo. Apesar disso, o PJU revelou-se como um poderoso instrumento de construção do consenso pelo processo de inserção precária desses jovens no mundo do trabalho. Nesse sentido, o programa desempenhou um papel de construção de redes de sociabilidade entre alunos que viviam a mesma realidade, mas secundarizou o acesso aos conhecimentos construídos historicamente pela humanidade.

$\mathrm{Na}$ verdade, o programa reduziu-se a uma das muitas iniciativas implementadas por diferentes instrumentos legais orientados para a formação da força de trabalho simples com um alcance planejado junto aos jovens e voltado, basicamente, para a adaptação psicofísica, a fim de moldar novos comportamentos exigidos pela fase da acumulação flexível, que não abdica das marcas sociais da assistência social arraigadas nas políticas educacionais como uma das principais formas de gestão da pobreza para não deixar "os pobres zangados" diminuindo possíveis conflitos sociais.

\section{Referências}

BILIO, R. de L. O Programa Nacional de Inclusão de Jovens-Urbano (ProJovem Urbano): A construção do precariado e a hegemonia da pequena política. 2017. 211 f. Tese (Doutorado em Educação) - Faculdade de Educação, Universidade Federal Fluminense, Niterói.

BRASIL. Decreto no 7.566, de 23 de setembro de 1909. Rio de Janeiro: República dos Estados Unidos do Brasil, 1909. Disponível em: $<$ http://www2.camara.leg.br/legin/fed/decret/1900-1909/decreto-7566-23setembro-1909-525411-publicacaooriginal-1-pe.html>. Acesso em: 15 ago. 2017. 
. Decreto $n^{\circ}$ 5.154, de 23 de julho de 2004. Brasília: Presidência da República, 2004. Disponível em: <http://www.planalto.gov.br/ccivil 03/ ato20042006/2004/decreto/d5154.htm>. Acesso em: 15 ago. 2017.

. Decreto $n^{\circ}$ 5.557, de 5 de outubro de 2005. Brasília: Presidência da República, 2005a. Disponível em: <http://www.planalto.gov.br/ccivil 03/ Ato20042006/2005/Decreto/D5557.htm >. Acesso em: 14 ago. 2017.

IBGE. Síntese de Indicadores Sociais, 2017. Disponível em: <https://www.ibge.gov.br/estatisticas-novoportal/sociais/trabalho/9221-sintese-deindicadores-sociais.html?\&t=downloads>. Acesso em dezembro de 2017

Lei no 11.129, de 30 de junho de 2005. Brasília: Presidência da República, 2005b. Disponível em: <http://www.planalto.gov.br/ccivil 03/ ato20042006/2005/lei//11129.htm>. Acesso em: 14 ago. 2017.

. Ministério da Educação. Conselho Nacional de Educação. Câmara de Educação Básica. Parecer CNE/CEB no 2, de 16 de março de 2005. Brasília: MEC, CNE, CEB, 2005d. Disponível em: $<$ http://portal.mec.gov.br/cne/arquivos/pdf/pceb002 05.pdf >. Acesso em: 14 ago. 2017.

. Ministério da Educação. Conselho Nacional de Educação. Câmara de Educação Básica. Parecer CNE/CEB no 37, de 7 de julho de 2006. Brasília: MEC, CNE, CEB, 2006c. Disponível em: $<$ http://portal.mec.gov.br/cne/arquivos/pdf/pceb037 06.pdf>. Acesso em: 15 ago. 2017.

. Lei no 12.513, de 26 de outubro de 2011. Brasília: Presidência da República, 2011c. Disponível em: <http://www.planalto.gov.br/ccivil 03/ ato20112014/2011/lei//12513.htm>. Acesso em: 15 ago. 2017.

. Medida Provisória $n^{\circ}$ 238, de 1ํ de fevereiro de 2005. Brasília:

Presidência da República, 2005c. Disponível em: $<$ http://www.planalto.gov.br/ccivil 03/ Ato2004-2006/2005/Mpv/238.htm>. Acesso em: 14 ago. 2017.

. Medida Provisória no 411, de 28 de dezembro de 2007. Brasília:

Presidência da República, $2007 . \quad$ Disponível em: $<$ http://www.planalto.gov.br/ccivil 03/ Ato2007-2010/2007/Mpv/411.htm>. Acesso em: 15 ago. 2017.

- Secretaria-Geral da Presidência da República. Secretaria Nacional de Juventude. Programa Nacional de Inclusão de Jovens. Projeto Pedagógico Integrado do ProJovem Urbano. Brasília: SGPR, SNJ, ProJovem Urbano, 2008a.

- Secretaria-Geral da Presidência da República. Secretaria Nacional de Juventude. Programa Nacional de Inclusão de Jovens. Orientações para a elaboração do Plano de Implementação do ProJovem Urbano para Municípios e Distrito Federal. Brasília: SGPR, SNJ, ProJovem Urbano, 2008b 
- Secretaria-Geral da Presidência da República. Secretaria Nacional de Juventude. Programa Nacional de Inclusão de Jovens. Relatório final do ProJovem - 2005 a 2008. Brasília: SGPR, SNJ, ProJovem, 2010a.

. Secretaria-Geral da Presidência da República. Secretaria Nacional de Juventude. Programa Nacional de Inclusão de Jovens. Sumário executivo avaliação do ProJovem Urbano (2008/2009). Brasília: SGPR, SNJ, ProJovem Urbano, 2010b.

- Secretaria-Geral da Presidência da República. Secretaria Nacional de Juventude. Programa Nacional de Inclusão de Jovens. Relatório de Gestão 2008-2010. Brasília: SGPR, SNJ, ProJovem Urbano, 2010c.

- Secretaria-Geral da Presidência da República. Secretaria Nacional de Juventude. Programa Nacional de Inclusão de Jovens. Survey II Educadores perspectiva comparativa entre as $1^{\mathrm{a}}, 2^{\mathrm{a}}, 3^{\mathrm{a}}, 4^{\mathrm{a}}, 5^{\mathrm{a}}$ e $6^{\mathrm{a}}$ entradas do ProJovem Urbano. Brasília: SGPR, SNJ, ProJovem Urbano, 2011a.

- Secretaria-Geral da Presidência da República. Secretaria Nacional de Juventude. Programa Nacional de Inclusão de Jovens. Relatório Gestores. Brasília: SGPR, SNJ, ProJovem Urbano, 2011b.

- Secretaria-Geral da Presidência da República. Secretaria Nacional de Juventude. Programa Nacional de Inclusão de Jovens. Dimensão: Práticas docentes. In: Cadernos temáticos do ProJovem Urbano. Brasília: SGPR, SNJ, ProJovem Urbano, 2011c.

CASTEL, R. As metamorfoses da questão social: uma crônica do salário.

Petrópolis: Vozes, 2008.

CUNHA, L. A. O ensino de ofícios nos primórdios da industrialização. São Paulo: UNESP, 2005.

FERNANDES, F. Capitalismo dependente e classes sociais na América Latina. Rio de Janeiro: Zahar, 1973.

GEREMEK, B. A piedade e a forca. História da miséria e da caridade na Europa. Lisboa: Terramar, 1995.

GRAMSCI, A. Cadernos do cárcere. Rio de Janeiro: Civilização Brasileira, 2006. V.1.

ILEASE. Anuário estatístico do Instituto Latino Americano de Estudos Socioeconômicos. Trabalho \& Exploração. O mapa da exploração dos trabalhadores no Brasil. October 7, 2017. N.8. Disponível em: http://ilaese.org.br/anuario-estatistico-do-ilaese-trabalho-exploracao/; $\quad$ acesso: dezembro de 2017.

LEHER, R. Para fazer frente ao apartheid educacional imposto pelo Banco 
Mundial: notas para uma leitura da temática Trabalho-Educação. In: MACHADO, Lucília; FIDALGO, Fernando; RUMMERT, Sonia Maria. Trabalho e Crítica Anuário do GT Trabalho e Educação/ANPED. Niterói: EDUF, 1999. P. 16-29.

MARX, K. O Capital: crítica da economia política (Livro Primeiro, vol. 1). Rio de Janeiro: Bertrand, 1988

PASTORE, J. Desigualdade e mobilidade social no Brasil. São Paulo: USP,1979.

PETRAS, J. Neoliberalismo: América Latina, Estados Unidos e Europa. Blumenau: FURB, 1999. (Coleção Sociedade e Ambiente, 3).

RUMMERT, S. M. Gramsci, trabalho e educação - jovens e adultos pouco escolarizados no Brasil actual. Cadernos Sísifo, Lisboa, n. 4, 2007.

RUMMERT, S. M. A modernização conservadora como marca da educação de jovens e adultos trabalhadores no Brasil. In: RUMMERT, Sonia Maria Rummert; CANÁRIO, Rui; FRIGOTTO, Gaudêncio (Orgs.). Políticas de formação de jovens $e$ adultos no Brasil e em Portugal. Niterói: Editora da Universidade Federal Fluminense, 2009, v. 1, p. 213-232.

RUMMERT, S. M.; ALGEBAILE, E.; VENTURA, J. Educação da classe trabalhadora: expressão do desenvolvimento desigual e combinado. In: Revista Brasileira de Educação, v. 18, p. 717-738, 2013.

RUMMERT, S. M.; BILIO, R.; GASPAR, L. ProJovem Urbano: a política transitória e emergencial como marca sócio-histórica na educação de jovens e adultos. In: BOMFIM, Maria Inês. e RUMMERT, Sonia Maria. Educação de Jovens e Adultos da classe trabalhadora brasileira. "Novos" projetos e antigas disputas. Curitiba: CRV, 2017.

SILVA, J. P. Políticas públicas de juventude e educação: as ações "emergenciais" na ótica de alunos do ProJovem Urbano. 2011. 101 f. Dissertação (Mestrado em Educação) - Centro de Ciências Humanas e Sociais, Universidade Federal do Estado do Rio de Janeiro, Rio de Janeiro, 2011.

VIEIRA PINTO, A. Sete lições sobre educação de adultos. São Paulo: Cortez, 2010.

VIRIATO, E. O.; CÊA, G. S. S.; CAVALCANTE, F. L. S. Reflexões sobre limites de pressupostos teóricos e de ações governamentais voltadas para a formação do trabalhador no Brasil à luz de Antonio Gramsci. In: CÊA, G. S. O estado da arte da formação do trabalhador no Brasil. Cascavel: EDUNIOESTE, 2007.

Recebido em: 21 de fevereiro de 2018.

Aprovado em: 03 de maio de 2018.

Publicado em: 21 de novembro de 2018. 